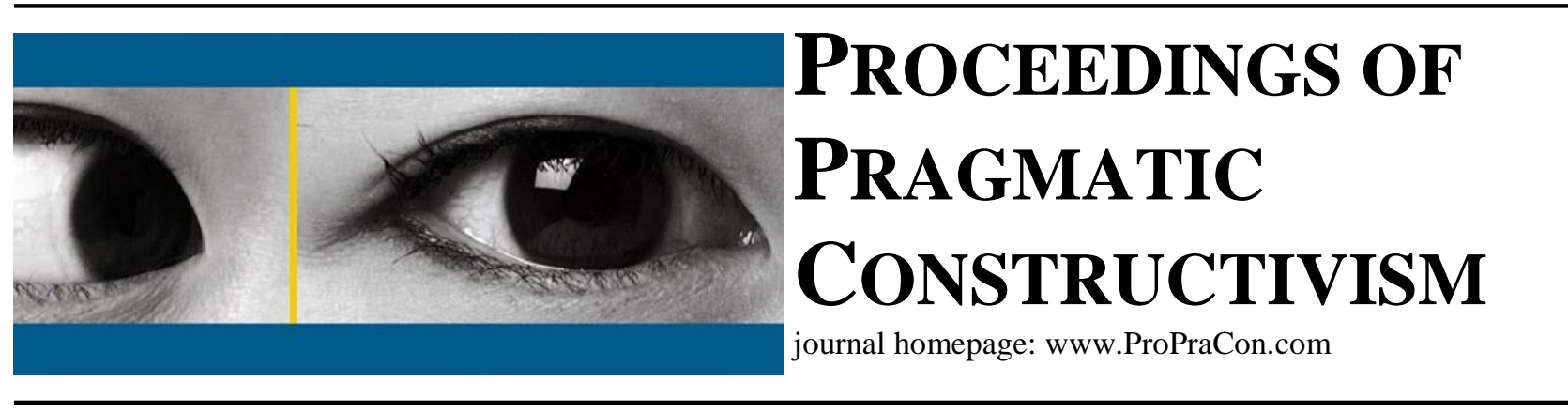

\title{
(Un)Performing Universities: the contradictory impacts of powerful numbers
}

\author{
Lino Cinquini \\ Scuola Superiore Sant'Anna of Pisa, Institute of Management \\ E-mail: l.cinquini@santannapisa.it \\ Cristina Campanale \\ Scuola Superiore Sant'Anna of Pisa, Institute of Management \\ E-mail: c.campanale@santannapisa.it \\ Sara Giovanna Mauro \\ Scuola Superiore Sant'Anna of Pisa, Institute of Management \\ E-mail: s.mauro@santannapisa.it \\ Andrea Tenucci \\ Scuola Superiore Sant'Anna of Pisa, Institute of Management \\ E-mail: a.tenucci@santannapisa.it
}

\section{Introduction - Research Background and Purpose}

Since the 1990s, a set of environmental factors has changed the scope of activities, structures and processes in universities (Alexander, 2000; Parker, 2002). These factors include the internationalization and marketization of universities (Ferlie et al., 2008; Hemsley- Brown and Oplatka, 2006), the increased national and international competition between institutions, and funding constraints (Alexander, 2000; Parker, 2002). Indeed, in a global market, there has been a shift in the governance of the Higher Education (HE) system through the introduction of marketization policies and market-type mechanisms (Alexander, 2000; Hemsley- Brown and Oplatka, 2006). Marketization has been considered a compromise between different forms of governance, as privatisation, academic autonomy and state control (Young, 2002). Therefore, a growing competition between universities has developed in search for accreditations and positioning in national and international rankings, symbols of the current evaluative culture (Dixon et al., 2013; Espeland et al., 2016). Furthermore, over the years, the State has tried to govern and steer better educational systems (Ferlie et al., 2008), by introducing mechanisms to link the allocation of resources to the results achieved (Alexander, 2000; Geuna and Piolatto, 2016) and by making performance evaluation compulsory for universities.

In this context, universities have started to measure and report their performance to account for their results for funding and demonstrate their good reputation. Thus, performance measurement systems (PMSs) have been adopted in universities and designed in a complex and multidimensional manner in order to measure performance at different governance levels, namely university, department and individual level, and to measure the three key areas of performance, namely research, teaching, and third mission.

Despite the widespread and continuous adoption and implementation of PMSs in universities, literature recognizes the perverse effects and concerns arising from rankings in university. We can recall the risk of standardization, the loss of creativity and freedom, the limitations of standards and rankings in assessing the quality of 
research that also include subjective evaluation (Humphrey and Gendron, 2015), and the challenges determined by PMSs in universities (Arnaboldi and Azzone, 2010; Modell, 2005).

In the attempt to colonize academics values, the HE proposed new academic values, identity and roles (Churchman, 2002; Parker, 2011; Agyemang and Broadbent, 2015) and determined a growing tension between "managerialist tyranny of excellence" and scholarly disciplines (Humphrey and Gendron, 2015) and between managers and academics' contrasting values (Boitier and Riviere, 2013).

This research aims at contributing to the debate on the impacts of managerialism and performance-driven reforms on the value systems in universities. To this aim, the research investigates the role of values in the adoption, implementation and perception of PMSs in universities in order to find out which values drive this process, which effects are produced in the value range of academic actors and how this transformation process is performed by the multiple actors involved. Figure 1 summarizes the rationale of the research.

Figure 1. Performance Measurement System in the Higher Education field

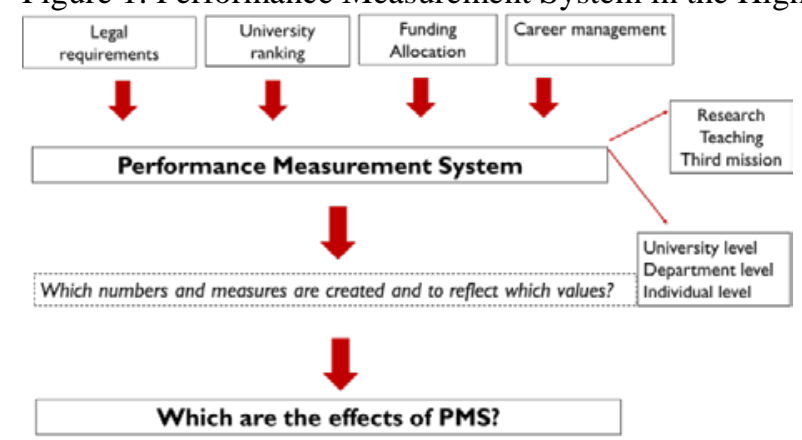

In order to achieve the research purpose, the research questions (RQs) are set as follows:

Which values are underlined in the evaluation criteria and goals designed and implemented by the actors at the national level?

How do managers at university level translate the national system in the university (local systems)? Which values are underlined in the PMS implemented at university level?

Which values motivate the work of academics? Has PMS been affecting their values over the years?

Do any contradictions between values at the different levels exist? How do contradictions co-exist?

\section{Methodology, Research Context and Research Method}

The changes occurring in the HE system, as discussed in the previous section, put universities under a growing pressure in order to manage the trade-off between the need for strategically positioning in the competitive market and the need for guaranteeing original, creative and inspiring research. This pressure underlines contradictions and tensions among different values (those of academics and those of reformers) and the tensions that reforms put to change existing values in universities.

The PMSs designed and adopted in the spirit of the widespread evaluative culture underline specific values which may be in contradiction with academics’ values. Moreover, PMSs may participate to reshape academics' values, promoting the search for scores and excellence rather than for innovativeness (Gendron, 2008; Guthrie and Parker, 2014). Performance measurement devices can influence what being an academic means nowadays.

Pragmatic Constructivism (PC) is a suitable lens for investigating the role of values in implementing, using and perceiving PMSs since it recognizes the relevance of values in determining actions (Nørreklit, 2017). In particular, PC distinguishes between basic values, which are the real motivators to act, and instrumental values that are functional to the achievement of basic ones.

This research intends to shed light on how this process takes place and how (and which) values lead this process influencing the actions of different actors.

\subsection{Research setting}

The research will be carried out in Italy, whose HE system has been influenced over the last years by demographic changes, economic crises and financial constraints, and by the new legislation's impact on university system (Dal Molin et al., 2017; Tieghi et al., 2018). In this latter regard, the legislative reform introduced a decade ago 
has made PMS compulsory for all universities, bringing significant changes in their governance structure and accounting systems. The reform has required universities to measure and report their multi-dimensional performance in ad-hoc documents, as performance plans and reports, to be published in order to reinforce transparency and accountability. In addition, the universities are object of a comparative assessment process based on the evaluation of their research activities. This research evaluation process is coordinated by the National Agency for the Evaluation of University and Research (NAVEUR), and involves experts (academics) selected per each disciplinary field who will contribute to elaborate the ranking of universities. Further, the agency is in charge of elaborating parameters to allocate funds, assessing programme results according to expected results and coordinating the activities of performance units, called "Nucleo di Valutazione", at the university level. These units, composed by academics and managers, collect, analyse and report the results of the evaluation activities carried out in universities in compliance with legislative requirements, in light of NAVEUR guidelines and compared to the performance objectives of the university. The tight financial constraints, the multidimensionality of PMSs and the numerous and powerful players involved at different levels make PMSs in universities in Italy complex and challenging, making this setting relevant for achieving the research purpose (Ryan et al., 2002).

In light of this context, the research will give voice to different actors (Figure 2), ranging from actors at the national level, who can be policy-makers, managers and academics, as members of the national agency NAVEUR, to actors at the university level, as the members, both administrative and academic, of the "Nucleo di valutazione", and, finally, the academic staff represented by employed actors as professors and researchers.

Figure 2. Values and actors in the empirical setting

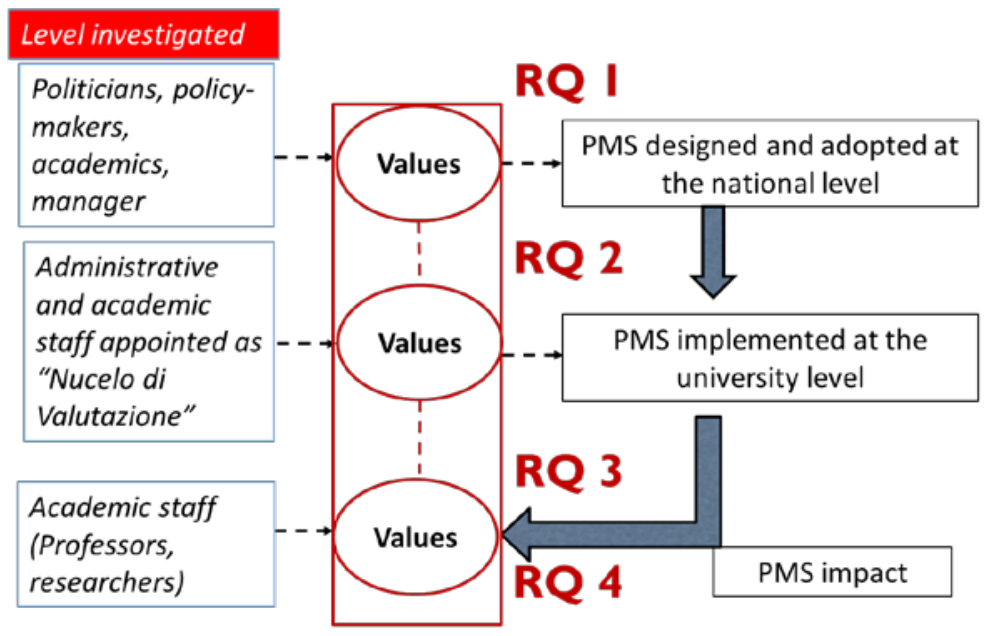

\subsection{Research method}

The research will be based on a comparative study of two cases selected according to the national ranking of universities elaborated by NAVEUR in two following years. The two cases are represented by one university that has improved its position in the rank from one year to another ("performing university") and one university that has worsened its position ("un-performing university”). Both the universities are similar in terms of geographical context and size, belonging to the class of medium-large universities, they are public universities and do not have international accreditations. In both the cases, we focus on the same disciplinary field. In this way, we wish to control other variables that can influence PMSs. The comparison between these two cases is expected to explore whether there are any differences among "performing” and "unperforming” universities in terms of how PMS is implemented and in its impact on actors' values.

The research will adopt a mixed-method approach. After a first preliminary analysis of documents, ranging from legislative documents disciplining the reform to the performance plans and reports elaborated by universities, the research aims at collecting empirical evidence in two steps:

Firstly, a survey tailored to academics in each university selected is designed to collect their opinions on PMSs, get an overall understanding of implementation and use of PMSs and identify their current values;

Secondly, semi-structured interviews will deepen the point of views of specific actors, selected at the different levels, namely national, university and individual, in order to achieve a more in-depth understanding of values driving the adoption and implementation of PMSs. 


\section{Expected contributions}

This research is expected to shed new light on how and why "numbers" may communicate new values in universities and influence their nature. We expect to find contradictions between the values of the actors at the different levels investigated. In this respect, it would be interesting to look at how these contradictions are managed. Furthermore, we expect that a process of change affected academics' values and it will be interesting to discuss this process.

The research can contribute to the existing body of knowledge about the effect of PMSs in universities and the effect on academics, through the lens of values investigation. In so doing, the research illustrates the leading role of actors' values and their "transformation" as steering mechanisms for the process of change of university. To this purpose, the PC approach is useful to investigate and understand how PMSs can function in universities allowing a new understanding of their functionality.

\section{References}

Agyemang, G., \& Broadbent, J. 2015. Management control systems and research management in universities: An empirical and conceptual exploration. Accounting, Auditing \& Accountability Journal, 28(7): 1018-1046.

Alexander, F. K. 2000. The changing face of accountability: Monitoring and assessing institutional performance in higher education. The Journal of Higher Education, 71(4): 411-431.

Arnaboldi, M., \& Azzone, G. 2010. Constructing performance measurement in the public sector. Critical perspectives on accounting, 21(4): 266-282.

Boitier, M., \& Rivière, A. 2013. Freedom and responsibility for French universities: from global steering to local management. Accounting, Auditing \& Accountability Journal, 26(4): 616-649.

Churchman, D. 2002. Voices of the academy: academics' responses to the corporatizing of academia. Critical Perspectives on Accounting, 13(5-6): 643-656.

Dal Molin, M., Turri, M., \& Agasisti, T. 2017. New Public Management Reforms in the Italian Universities: Managerial Tools, Accountability Mechanisms or Simply Compliance?. International journal of public administration, 40(3): 256-269.

Dixon, R., Arndt, C., Mullers, M., Vakkuri, J., Engblom-Pelkkala, K., \& Hood, C. 2013. A lever for improvement or a magnet for blame? Press and political responses to international educational rankings in four EU countries. Public Administration, 91(2): 484-505.

Espeland, W. N., Sauder, M., \& Espeland, W. 2016. Engines of anxiety: Academic rankings, reputation, and accountability. Russell Sage Foundation.

Ferlie, E., Musselin, C., \& Andresani, G. 2008. The steering of higher education systems: A public management perspective. Higher education, 56(3): 325-348.

Gendron, Y. (2008). Constituting the academic performer: the spectre of superficiality and stagnation in academia. European Accounting Review, 17(1): 97-127.

Geuna, A., \& Piolatto, M. 2016. Research assessment in the UK and Italy: Costly and difficult, but probably worth it (at least for a while). Research Policy, 45(1): 260-271.

Guthrie, J., \& D. Parker, L. 2014. The global accounting academic: what counts!. Accounting, Auditing \& Accountability Journal, 27(1): 2-14.

Hemsley-Brown, J., \& Oplatka, I. 2006. Universities in a competitive global marketplace: A systematic review of the literature on higher education marketing. International Journal of public sector management, 19(4): 316-338.

Humphrey, C., \& Gendron, Y. 2015. What is going on? The sustainability of accounting academia. Critical Perspectives on Accounting, 26(C): 47-66.

Modell, S. 2005. Students as consumers? An institutional field-level analysis of the construction of performance measurement practices. Accounting, Auditing \& Accountability Journal, 18(4): 537-563.

Nørreklit, L. 2017. Actor-Reality Construction. In H. Nørreklit (Ed.) A Philosophy of Management Accounting: 37-85. Routledge.

Parker, L. 2002. It's been a pleasure doing business with you: a strategic analysis and critique of university change management. Critical Perspectives on Accounting, 13(5-6): 603-619.

450 .

Parker, L. 2011. University corporatisation: Driving redefinition. Critical Perspectives on Accounting, 22(4): 434-

Ryan, B., Scapens, R. W., \& Theobald, M. 2002. Research Methods and Methodology in Finance and Accounting (2nd ed.). Stamford, CT: Cengage Learning.

Tieghi, M., Orelli, R. L., \& Padovani, E. 2018. Accounting Reform in Italian Universities. Internal Response to Accounting Change. Management Control, 1: 117-138.

Young, S. 2002. The use of market mechanisms in higher education finance and state control: Ontario considered. The Canadian Journal of Higher Education, 2: 79-102. 